\title{
Education and capacity building with research: a possible case for Future Earth
}

Education and capacity building

Yasuhiro Fukushima

Department of Chemical Engineering, Tohoku University, Sendai, Japan

Gakushi Ishimura

SANRIKU Fisheries Research Center, Iwate University, Kamaishi, Japan

Andrew James Komasinski

International Division, Hokkaido University of Education, Asahikawa, Japan

Reiko Omoto

Research Institute for Humanity and Nature, Kyoto, Japan, and

Shunsuke Managi

Kyusyu University, Fukuoka, Japan

\begin{abstract}
Purpose - This paper aims to suggest the structure of a platform for education and capacity building for Future Earth, which is an intensive program open to the eight stakeholders and which utilizes existing research programs/facilities associated with Future Earth. An intention of this paper is to facilitate a policy brief for projects associated with Future Earth.

Design/methodology/approach - This paper reviewed backgrounds and necessary items for education and capacity buildings in Future Earth projects by implementing three main priorities in Future Earth and current surrounding environments.

Findings - This paper then suggested a possible structure, competencies, contents and human resources for education and capacity building and education for Future Earth.

Originality/value - The suggestions can be implemented in capacity building and education programs associated with Future Earth.
\end{abstract}

Keywords Education, Sustainability, Capacity building, Future Earth, Human resource

Paper type Research paper

\section{Introduction}

This paper maps out an education and capacity building framework for implementing Future Earth in the Asia-Pacific Region. As a regional policy framework prospectus, this document outlines possible steps for success in the implementation of a long-run strategy that accomplishes continuously improving communications and decision-making systems.

(C) Gakushi Ishimura, Yasuhiro Fukushima, Andrew Komasinki, Reiko Omato and Shunsuke Managi. Published by Emerald Publishing Limited. This article is published under the Creative Commons Attribution (CC BY 3.0) licence. Anyone may reproduce, distribute, translate and create derivative works of this article (for both commercial and non-commercial purposes), subject to full attribution to the original publication and authors. The full terms of this licence may be seen at http://creativecommons.org/licences/by/3.0/legalcode

Received 24 October 2015 Revised 23 August 2016 Accepted 31 August 2016

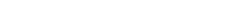


IJSHE

18,2

264
Future Earth is a research initiative that will:

- develop our capacity for responding to the risks and opportunities raised by global environmental change; and

- transform our society toward global sustainability.

Future Earth is the flagship policy framework designed to replace prior incomplete and inadequate strategies for the future of the planet and the life that inhabits it. The core feature of Future Earth lies in its approach to involve stakeholders in the knowledge creation and systems transformation process toward sustainability. Human society and the ecosystem are both dynamic, and this means that the solutions too must be both immediate and continuous. To meet these needs requires a transdisciplinary approach, which in turn requires the establishment of an educational framework to give the current and a new generation of leaders competency and capacity building (Reid et al., 2010). Thus, education and capacity building are necessary and integral for the sustainability of Future Earth and the sustainable future it seeks (Future Earth, 2013).

Here, the central concern is the limited carrying capacity of the ecological services and natural resources the Earth provides, which cannot be overcome through economic growth (Arrow et al., 1995). This includes climate change, the need for alternative and renewable energy sources, loss of biodiversity, improvements of well-being poverty, dwindling natural resources and economic instability (UNESCO, 2014). Tackling these concerns requires seeing society and nature as a complex integrated system; one that is globally connected; one that links current and future generations. Over the past century, the global economy has grown by leaps and bounds, and the overall well-being of the Earth's citizens has substantially improved with longer life expectancies, reduced hunger and less poverty in developed nations. Yet, this is not true for the entire world - particularly for developing nations, which hold most of the world's population. In the next century, qualitative improvements through the cooperative efforts and achievements of both developed and developing nations, with explicit consideration given to the inequality of the North-South divide, must be sought.

From 2005 to 2014, the UN Decade of Education for Sustainable Development (ESD) promoted the mobilization of educational resources of the world to help create a more sustainable future (UNESCO, "ESD: Mission"). Yet, there is a critical need in Future Earth to take over their achievements in ESD and accelerate our efforts toward Global Sustainability to train eight stakeholders in Future Earth: research, science-policy interfaces, funders, governments, development organizations, business and industries, civil society (nongovernmental organizations, etc.) and media (Future Earth, 2013).

The sustainability challenges facing the Asia-Pacific region are daunting in scale. The Asia-Pacific region has the majority of the world's population, believers in all of the world's major religions and a total regional economy larger than the USA or the European Union. Additionally, more than 20 countries and areas greatly vary from aging developed areas such as Hong Kong, Australia and Japan facing population decline to youthful middle-income and developing nations such as Malaysia, Indonesia and Cambodia with booming populations (Lee and Hong, 2012). As such, policies in the Asia-Pacific region must look not only at the eight stakeholders in Future Earth but also attend to the complex historical and political realities of the region and then navigate these toward international cooperative transnational policies and initiatives.

\section{Policy recommendations}

The education and capacity-building framework for Future Earth should focus on the following two areas for education and capacity building. First, there is a need for educational 
reforms toward key sustainability competencies (Wiek et al., 2011) to grow the capacity of the Asia-Pacific as an innovator for progress toward Future Earth. Second, there is a need for a solutions-oriented project approach at the local, national and transnational levels. This includes transnational sustainability initiatives that have universities in various regions as a core, and many stakeholders from countries where the university is located will be necessary to accelerate the steps of transformation through capacity building.

It is our belief that to accomplish Future Earth, quantifiable change on each of the three central competencies, "critical thinking", "normative dialogue" and "transformative leadership" proposed for educational reform, must be seen. Outcomes in each of these areas are measurable, and their accomplishment will have a substantial impact on Future Earth achievements. Critical thinking is indispensable as a tool to synthesize problems and their solutions reiteratively. Normative dialogue is important as the ability to understand and work with diverse opinions and ideas about values. Transformative leadership is the capacity to implement solutions in diverse stakeholder contexts. A common framework built on key competencies implemented through educational reforms and cultivated through shared projects will enable the realization of Future Earth for the diverse stakeholders involved.

For competency-based education, this would involve curriculum changes implemented by the ministries of education in the highly developed and middle-developed countries to require further coursework in critical thinking (an educational reform also sought by the Organisation for Economic Co-operation and Development (OECD); See Froese-Germain, 2010), intercultural understanding and transformative leadership.

For the solution-oriented projects, highly developed countries should lead by, for example, in Asia, taking responsibility for implementing trans-national initiatives. Middledeveloped countries in turn should undertake trans-national initiatives and several domestic initiatives. Low development countries should work with nations of abundance on cooperative projects and have leadership responsibilities for the ones that occur in their own countries. Moreover, to enhance the capacity for sustainability in these countries, abundant opportunities should be available for students from less developed countries to study abroad in more developed countries. The envisioned transnational sustainability initiatives will create lots of interfaces between universities with resources in developed countries, universities with near-access to the sustainability issues and stakeholders of all kinds in partner countries. The idea here is not that the richer countries would colonize the poorer with sustainability but rather that they would enable the universities in the poorer countries to become independent leaders in sustainability and to serve as bases for further competency building in their own countries through cooperation. Such cooperation would also bring about crucial benefit to the universities in the developed countries by allowing closer attachment with the most challenging problems of the region.

\section{Implementation priorities}

Future Earth is designed to build on and transform existing projects and infrastructure, rather than reinventing everything de novo. What Future Earth adds is a holistic perspective incorporating all eight stakeholders and guidance from the conceptual research themes of Future Earth. By incorporating all stakeholders, Future Earth projects are more responsive to the needs of the societies they wish to transform, making the projects more autonomous and sustainable. Moreover, the projects are also capacity building and pedagogical in function, as they encourage co-design and co-production of knowledge and solutions utilizing the competencies of all stakeholders.

Future Earth sets out three priorities for education and capacity building as follows: 
IJSHE

18,2

266

(1) to establish effective and sustained collaboration across and between the regions;

(2) to support a culture of transdisciplinary research and a holistic thinking among other stakeholder groups regarding global environmental change and sustainable issues; and

(3) to facilitate the uptake of scientific findings in policies and practices to advance transition toward global sustainability at all levels.

This policy paper sets out to examine how these priorities can be reasonably implemented in the Asia-Pacific region under the Future Earth initiative.

\section{Potential program structure in the Asia-pacific policy framework}

Within the Asia-Pacific region, the researchers suggest that there are three main education and capacity building goals. First, there is the task of building relevant competencies in stakeholders. This supplies the necessary skills for multi-stakeholder collaborations to succeed. Second, there is a need to cultivate "bilateral translators", those who can facilitate the accomplishment of important Future Earth sustainability projects by bridging the skills and needs of different stakeholders. Finally, there is the implementation of Future Earth projects, which can be built on existing programs and networks conducting the global environmental change research from their on-going achievements (Future Earth, 2013).

Every Future Earth Asia-Pacific education and capacity building project should have a focus issue. Moreover, the issue must be understood in such a way as to involve all eight stakeholders, match their capabilities and involve their concerns. Through the projects, stakeholders will use their expertise and competencies, learn from each other and work together to implement sustainability solutions through joint research, scaled demonstration and shared implementation (Lang et al., 2012).

The achievement of both types of goals is essential to meet the challenges of the Asia-Pacific region and to help bridge the massive inequalities that exist within the sector to move toward a sustainable planet.

Educational competency goals for Future earth

The development of suitable education and capacity building programs for Future Earth that achieve global sustainability requires the establishment of a common platform for education and capacity buildings for Future Earth. This requires moving beyond a conventional model where universities exist to produce researchers with singular specializations. Instead, the education and capacity building for Future Earth commences with:

- building a common understanding of mechanisms, causes and solutions for the central challenges Future Earth addresses; and

- nurturing competencies to resolve Future Earth problems to lead to global sustainability.

At the heart of this is the need for transdisciplinary collaborative research and problem-solving that bridge disparate fields and incorporate "non-academic stakeholders from business, government, and the civil society” (Lang et al., 2012, p. 26; Mauser et al., 2013). To accomplish this, Future Earth builds on key competencies (Wiek et al., 2011) that lead to a correspondence between our scientific understanding and the real world as it is. Global sustainability issues such as the resolution of environmental degradation, global warming, poverty reduction, improving well-being and the alleviation of global health problems require complex, interdisciplinary approaches with specific competencies. Eight stakeholders 
armed with both cutting-edge technologies and knowledge from the outcomes of Future Earth, from diverse backgrounds (careers, academic training and motivation), are called upon to seek and execute alternative solutions to the challenges posed by a focal point issue.

Although the framework of competencies is helpful, Wiek et al. (2011, p. 212) points out that both the precise list of competencies and the production of "graduates [who] are skilled enough to tackle sustainability problems" remain elusive. Yarime et al. (2012) similarly points out the difficulty in finding an effective curriculum for the sort of integrative research that sustainability science demands.

Within the Asia-Pacific region, the authors highlight the following three competencies and their cultivation as central to solving challenging sustainability issues on both the local and global levels: critical (or logical) thinking that gives the ability to structure the issue explicitly, normative dialogue as the ability to engage profitably in discussions with stakeholders with diverse interests and backgrounds and still produces a common agenda on how to resolve the issue and transformative leadership to both formulate a vision and help activate the stakeholders to reach a dynamic solution to the problem.

Competency I: critical thinking. The first and keystone competency is critical thinking. Unfortunately, this, as with many terms in the competency literature (Wiek et al., 2011), is not sufficiently clear by itself. The OECD has recently emphasized on the importance of critical thinking and is in the process of adding conceptual problem-solving to its evaluative framework for education throughout the developed world (OECD, 2005; Froese-Germain, 2010).

Critical thinking has also appeared in various ways within sustainability science research as a competency. Thomas (2009) notes the need for "problem-solving skills in a nonreductionist manner for highly complex real-life problems" within the context of education for sustainability. Others also identify "reflexive competency" (Mochizuki and Fadeeva, 2010) or "reflectiveness". This may be what Wiek et al. (2011) define as "problem-solving competence".

The Delphi report produced under the aegis of the American Philosophical Association provides a helpful definition of critical thinking the authors will build on (Facione, 1990, p. 2):

We understand critical thinking to be purposeful, self-regulatory judgment which results in interpretation, analysis, evaluation, and inference, as well as explanation of the evidential, conceptual, methodological, criteriological, or contextual considerations upon which that judgment is based. Critical Thinking is essential as a tool of inquiry.

Within this definition, the core skills are those cognitive skills that enable "(1) interpretation, (2) analysis, (3) evaluation, (4) inference, (5) explanation and (6) self-regulation" (Facione, 1990, p. 4). Understood in this way, these skills form a keystone competency for sustainability science, which can itself be understood as excellence in correctly identifying the issues at hand, understanding how they and the stakeholders are related, outlining a solution that achieves the goals of Future Earth and finding the means of implementation.

Education that cultivates competency in critical thinking requires a multi-pronged approach. First, steps must be taken to develop the basic thinking skills of the eight stakeholders with basic informal logic and train them in the classroom to identify their solutions and discuss implementations. This, by itself, however, will only give a peripheral competency. Second, the curriculum should have students consider model problems that begin to mirror real-world complexity - not merely simulations that produce predictable results, but situations that require them to solve both resource management and human problems. Third, all eight stakeholders must be involved in the thought process that considers wickedly complex problems so that they will be able to tackle the more difficult 
IJSHE

18,2

268

problems which remain unsolved and thus enable the sustainability scientists of the future make Future Earth a reality.

Competency II: normative dialogue. A second core competency is normative dialogue. This term is helpfully placed in the taxonomy of Wiek et al. (2011), but the reference there is as Wiek et al. (2011, p. 212) note in their own discussion ambiguous in an unfortunate and potential colonial way. To flesh out the problem, the use of normative competency insofar as it does not specify whether it means the ability to abstract from one's own moral bearings or the ability to enforce one's views onto others means that this could be a bludgeon to enforce ideological normativity. To avoid this, the authors elect to use the term "normative dialogue" and explain below that the capacity the authors maintain is needed for Future Earth progress toward sustainability in the Asia-Pacific context.

Future Earth research always faces moral thinking in the decision-making, because it concerns the trade-off between current human well-being and future ones, North-South dynamics and the rich and the poor in light of biased and intensive uses of environment and natural resources (WCED, 1987). In addition, global sustainability needs to consider the well-being not only of parties local to the problem but also of those more distant and prudently weigh these considerations appropriately.

Much of the current ethics education in sustainability science is overly truncated with the assumption that a common view is the correct one or that there is only one side to each moral problem. This sort of thinking is especially problematic in Asia, which contains great diversity in terms of worldview and religion. Although all of these traditions do in their own ways value the Earth, their expressions and implementations of this care differ greatly. Lack of training for normative dialogue poorly equips future sustainability scientists for the humanistic angles of development problems, blinding them to the real moral concerns from other viewpoints. Competency in normative dialogue is both knowing what you think is right and wrong and knowing that this is what you think - the awareness that our own norms, values, attitudes, beliefs and assumptions are guiding our perception, our thinking, our decisions and actions within such sustainability issues. Through this, the eight stakeholders can reduce or avoid the danger of ethnocentrism in assuming that one's moral framework is the only possible one. Moreover, translators who are conscious of this can work with the difficulty that broadly shared ideals can admit of various and incompatible interpretations (Hadorn et al., 2006). This is a competency precisely because it enables us to structure our Future Earth activities around self-reflective global consensus.

Competency III: transformative leadership. The third key competence is transformative leadership. Leadership is an interpersonal process whereby an individual (leader) influences a group of individuals (followers) to achieve a common goal (Yukl, 2010). A group is a collection of subsystems that operate together to achieve the goals by using socio-technical production processes (Katz and Kahn, 1978). To maintain this process, it is necessary for a team (or group) to extract resources from its surrounding environment and set a common goal that is likely to attract effort and investment by individual team members (Mumford et al., 2000). As a central point of interpersonal dynamics between leaders and followers, leadership is an indispensable part of this process.

Burns (1978) was the first to describe the theory of a transformational leader in leadership studies. A transformational leader performs leadership involving an interactive relationship with his or her followers using two elements; making followers more aware of the importance and value of task outcomes and transcending their own self-interests for the sake of the team. Through this process, both a transformational leader and his/her followers pursue self-actualization - a common goal of any team (Sun and Anderson, 2011). This 
self-actualization process requires a transformational leader to be both visionary in introducing radical changes wherever necessary to achieve.

Within the sustainability literature, Wiek et al. (2011, p. 210) place the idea of effecting change under the title "strategic competence". The component of leading that involves task of working with others is in turn placed under "interpersonal competence" (p. 211). This is joined with emerging consensus that leadership is of critical importance of leadership for sustainability (Akiyama et al., 2012; Metcalf and Benn, 2012).

One of the key skills in transformational leadership is the ability to formulate clear and appealing visions of what a team can accomplish and to provide the directions necessary for followers to understand the goals, objectives and priorities of the team. It is necessary to share a vision that illuminates the path to a better future by solving issues. A vision needs to be attractive enough for followers to justify devoting their efforts. Only by articulating a compelling vision can a transformational leader build an effective and well-performing team.

As the eight stakeholders tasked with problem-driven projects on a focal point issue in Future Earth are often required to bring about radical changes within limited time durations, transformational leadership is a necessary competency within the platform for education and capacity building for Future Earth.

\section{Bilateral translators: human links between research, policy and implementation}

Future Earth with the specific goal of closing the gap between environmental research and current policies and practices (Future Earth, 2013) needs human assets that can enable communication within/between the eight stakeholders. Moreover, stakeholder involvements in Future Earth should shift from mere consultation involving passively being consulted to full dialogue where all stakeholders are full agents working toward realizable solutions.

The Integrated Local Environmental Knowledge project for Research Institute of Humanity and Nature (Sato, 2014, p. 210) defines "bilateral translators" as individuals who stimulate the utilization and promote sharing of scientific knowledge among the stakeholders. In doing so, they evaluate and re-organize knowledge from the perspective of respective stakeholders and translate the diverse knowledge accumulated among stakeholders into more general conventional languages (ILEK project, 2016). These bilateral translators, such as Brundiers et al.'s (2013, p. 4615), "transacademic interface managers" or Williams' (2002, p. 103) "boundary spanners", seek to usher in a new era of cooperation in research. Bilateral translators who can "stitch" together common features out of different values and interests expressed by various stakeholders can be at the center of this communication.

To bring thestakeholder involvement up to the desired level, "bilateral translators" should stimulate the utilization and sharing of both general and specialized (scientific) knowledge; and facilitate co-design and co-production in research projects, and to co-deliver the results, supporting essential decisions should to be made to support for the transformation of the society. The bilateral translators are also expected to address current gaps in core competencies and gaps between researchers and other stakeholders. Therefore, during the transitional stage where the education platform has not yet integrated the three competencies, bilateral translators will have special importance.

There already are large amounts of knowledge, including scientific discoveries, humanistic knowledge and indigenous or local information, and new research is happening continuously. This growth will continue but does not by itself lead to a sustainable future. To transform society toward global sustainability, bilateral translators will need thorough knowledge of the key competencies identified above to bridge the:

[...] widely acknowledged challenges of collaborations across different communities of knowledge and values. Such collaborations demand bridging different worldviews, ways of knowing, 
IJSHE

18,2

270 motivations, interests, and power positions, which often are incommensurable or even conflicting (Brundiers et al., 2013, pp. 4619-4626).

Moreover, working from Wiek et al. (2011), they should have both normative dialogue competence and "interpersonal competence" to play well with others, critical thinking skills to properly grasp problems and "strategic competence" to work toward solutions through transformational leadership (Brundiers et al., 2013, pp. 4620-4628). In other words, their job is to bring about the utilization of the cumulative wealth of the stakeholders for a solution-based approach to sustainability problems.

\section{Focal issue projects}

Focal issue projects can and should occur on multiple scales:

- short-term pilot exchange projects built around Future Earth's core priorities;

- domestic university-led local transdisciplinary eight-stakeholder cooperative sustainability initiatives; and

- transnational cooperative sustainability initiatives (especially partnerships across of the economic development spectrum).

Framing rigid and artificial conceptual boundaries around either natural or social systems can hamper what might be termed as a more holistic understanding of the suppressed problems humanity and the planet as a whole are facing (Paula et al., 2010). Building on the eight-stakeholder model of Future Earth, the authors maintain that focal issues should be addressed in a transdisciplinary and solution-oriented manner. One major outcome of all of this is the production of "bilateral translators".

\section{Pilot exchange projects}

Short-term pilot implementations could range from three days to two weeks. These are designed to provide all eight stakeholders an opportunity to contribute to the platform without overly interrupting their primary occupations. Such a program would lay the foundation for later, more intensive collaboration by training participant stakeholders in the Future Earth education and capacity building platform. These programs would be primarily local but could involve exchanges to involve and prepare others to host their own pilot programs.

One of pilot exchange programs is an intensive workshop to focus on the sustainable use of fishery resources, the International Education Program for Sustainable Fishery Resources. This project is developed and operated by the Graduate School of Fisheries Science and the Center for Sustainability Science at Hokkaido University (Japan).

This course is designed as an intensive program for sustainability science available for people with diverse backgrounds and interests using sustainable use of fishery resource as its local course. Training Ship (T/S) Oshoro Maru has been participating in ocean/fishery observations and research in the North Pacific over 100 years from the Oshoro Maru I (1909-1927) to current Oshoro Maru V (2014 onward) and has made significant contributions to fishery and ocean research in the North Pacific.

Participants attend ten days of interdisciplinary lectures focusing on sustainable fishery resource use, participate in a three-day cruise on-board the training ship Oshoro Maru (T/S Oshoro Maru), visit local fishing industry facilities and work together on group projects focusing on the global and local sustainable use of fishery resources.

This program consists of four components: lectures, site-visits, on-board training and group work for action proposals for the local community built on the sustainable use of 
fishery resources. These activities aim to create a shared vision through a convergence of interests and concerns raised by diverse perspectives on the use of fishery resources by using Southern Hokkaido region as an example. In addition, at Hokkaido University, competency trainings for logical thinking, normative dialogue (as a part of environmental ethics) and leadership (as a part of environmental leadership) are provided as a part of sustainability science certificate program. Until now, over 50 participants (graduate students and governmental officers) from over 20 countries have participated in this program.

Education and capacity building

\section{Domestic-led local transdisciplinary projects}

These projects would be longer in term than pilot projects and involve sustained commitments from the stakeholders to make progress on Future Earth sustainability issues. These projects would take the form of "solution-oriented sustainable research", which is applied to real-world sustainability goals (Miller et al., 2014, p. 240) and has been modeled at Arizona State (Wiek and Kay, 2015), and the kashiwa-no-ha collaborative initiative involving the University of Tokyo, Kashiwa city, Chiba University and others that focused on building a low-carbon city (Trencher et al., 2015).

One model of this in Asia is the Tanegashima hatsuga forum. Tanegashima is a remote southwestern Japanese island at the frontier of sustainability problems, such as aging, declining young population, job displacement and changes in climate, environment and natural assets. The forum provides a space for interaction between multiple stakeholders including industry, research, academia, government and corporations. Thus, the forum involves the co-creation of knowledge (Mauser et al., 2013).

One of the major accomplishments of the forum has been to integrate the energy resources of the self-sustaining sugar cane industry with the energy needs of other stakeholders on the island. What this has meant in practice is that the forum has sought to integrate resources from multiple disciplines to change cultivar and cropping methods of sugarcane grown on this island, implementing a new sugar extraction process (Ohara et al., 2012, 2013; Ouchida et al., 2016), making the sugar mill more efficient in terms of energy utilization (Ouchida et al., 2016) and establishing heat and power sharing among the industries and residents on this island (Kikuchi et al., 2016) for sustainability.

A key component has been the use of bilateral translators to bridge the disparate worlds of the stakeholders. As the forum's efforts succeed, the island and its capacity will become an asset for capacity building, especially for similar science-based island revitalization projects. This project provides a capacity building platform for Future Earth through student mentoring and also allows for research and training related to all eight stakeholders in the Future Earth model.

These projects involve the cooperation of all stakeholders, and this changes the function from one that is researcher-led and focused to one where instructors and educational institutions could primarily undertake a feedback and a coaching role (Wiek and Kay, 2015). Instead, learners become the active agents and interact directly with stakeholders to produce solutions and gain practical experience with competencies and multi-stakeholder environments (Wiek and Kay, 2015).

As Wiek and Kay (2015, p. 29) note, traditional models of education "leave students ill-prepared", and competencies are "best conveyed in real-world learning settings" (Brundiers and Wiek, 2013). For that reason, the authors maintain that it is vitally important to build on the key competencies of critical thinking, normative dialogue and transformational leadership. These competencies, which center on "how to think", work in tandem with the domestic transdisciplinary projects, which will represent a core feature for 
IJSHE

18,2

implementation in the Future Earth Asia-Pacific education and capacity building framework.

Multi-national mentoring projects

The purpose of these projects is both to find solutions for larger-scale sustainability and to empower stakeholders in less developed nations to approach and solve national problems in sustainability. Similar efforts are underway and being tracked through regional and international websites and networks such as the UN Sustainability Development Research Programme and the Latin America region Evidence and Lessons from Latin America platform[1].

As Future Earth progresses, the common platform of education and capacity building for Future Earth will increasingly interconnect the eight stakeholders in a cooperative framework for integrated Future Earth research. For researchers, this will provide a Future Earth stakeholder community that requests research, maintains dialogue during the project and reacts quickly to findings. For the other stakeholders, this framework provides outcomes-oriented research output; direct access to experts; research outcomes and innovations within the research framework; and dynamically responsive research teams.

\section{Discussion and conclusions}

The authors envision this platform having a role in resolving open natural resource problems, water shortages, lower-wetland management for carbon emissions and pollution-related issues at the local and regional level and issues of economic disparity within the Asian sector. Already established institutes and programs undertaking research associated with Future Earth will facilitate the opportunities for the common platform of education and capacity building for Future Earth. For example, Science and Technology Research Partnership for Sustainable Development (SATREPS) programs[2] initiated by Government of Japan that promote international joint research which targets global challenges and requires engagement by the international community can serve as candidates to facilitate a common platform for education and capacity building for Future Earth. A wide range of global/regional environmental issues (e.g. wild fire managements for carbon management and water resource management with sanitation system) ${ }^{3}$ has already been studied through the international networks developed by SATREPS. The initial design of Future Earth is committed to utilizing already established programs and networks for education and capacity building. Candidate programs for education and capacity to provide human assets for Future Earth should urgently be identified, consulted and prepared to incorporate and advance a common platform for education and capacity of Future Earth.

The competencies of critical thinking, normative dialogue and transformational leadership are not inherently controversial. In fact, global initiatives outside of Future Earth are already in motion to improve education in terms of critical thinking and transformational leadership (Froese-Germain, 2010). What our paper suggests is that the vocabulary gap between sustainability science's "problem-solving competency" and "strategic competency" (Wiek et al., 2011, p. 205, p. 210) and the vocabulary used in educational contexts which calls them "critical thinking" and "transformational leadership" (Facione, 1990, p. 1; Burns, 1978, p. 36) must be bridged. As many of these initiatives are already under way, the main task is integrating Future Earth with this work. Progress in terms of normative dialogue may prove more difficult, but it is vitally important for Asia as a center of diversity. Some of the theoretical work is already being done (Kassiola, 2003; Peleg, 2010), but incorporation into education lags behind the other two key competencies.

The importance of "bilateral translators" in the proposed framework is high. However, the process for producing these valuable human assets is a subject for further research. One 
assumption that needs to be validated through present and future examples is the role of outsiders as opposed to natural stakeholders. Although sometimes they would appear from within the stakeholders as natural members of a project, it is also quite likely that they will be brought in as relative outsiders. An outsider, by definition, has no particular stake in the region. For instance, they represent neither industry nor consumers. Ideally, what they can bring is high competency (especially in the competencies identified in this article) and direct experience in regional, solution-oriented projects.

Generally, being outsiders with high competency and no specific local stake may work as

Education and capacity building

a plus for a bilateral translator, because they have advantages in winning the trust of the various and diverse stakeholders at the same time, and they consider their positions more calmly and carefully than an invested party. Participatory approaches in development projects facilitate process of local empowerment, allow the integration of local knowledge systems into local project planning and implementation, facilitate a two-way learning process between the local community and the project and build a common understanding between institutions and local groups (Oltheten, 1995, Chapter 1). The authors expect that bilateral translators will be able to catalyze implementation of this participatory approach but in the updated context of transdisciplinary process (co-design, co-production and co-delivery of knowledge) in Future Earth. Prior work has reviewed the framework of participation (Reed et al., 2013, Hassenforder et al., 2015) and has not contained descriptions of the capacities and characteristics of the human assets necessary to make such a framework successfully operate. The reason the authors recommend better highlighting solution-oriented projects in the context of capacity building is based on an assumption that this type of capacity is often identified through solution-oriented projects. Through successful examples of such projects, common features on emergence of bilateral translators should be studied more in detail. Similarly, further work should be done, based on successful projects, in identifying how outsiders can be accepted as partners in the process, as "development projects are by definition external interventions" (Oltheten, 1995, Chapter 1).

This paper presents an education and capacity-building framework for implementing Future Earth in the Asia-Pacific Region. The Future Earth education and capacity building priorities specify important education goals. They also provide a framework for cooperation among human assets in the form of the eight stakeholders. Bilateral translators supplement these individual stakeholders within this framework. From this, the authors identify two key policy recommendations. First, the paper calls for the implementation of educational reforms already, which are in-line with OECD expectations, to build capacity in three core competences.

Second, the paper calls for the implementation of transdisciplinary projects and promoting solution-oriented projects and capacity building projects. These projects can occur on three different scales, but all are directed toward the co-implementation of transformation and capacity building tasks. What remains is to further work out in detail how each country in the Asia-Pacific region can be involved to more precisely identify bilateral translators and their roles and to identify capacity and apply it to Future Earth related projects.

\section{Acknowledgements}

This research was partially funded by Grant-in-Aid for Specially promoted Research (26000001) from the Japanese Ministry of Education, Culture, Sports, Science and Technology (MEXT) and was supported by the Environment Research and Technology Development Fund (S-14), under the Japanese Ministry of the Environment. 
IJSHE

18,2

274

This paper builds on research presented at the Science Council of Asia 14th Annual Conference 2014, Symposium: Towards Establishing a Common Nucleus Among Eight Stakeholder Groups: Education/Capacity Building for Future Earth. This panel brought together members from Japan, Taiwan and America, working at different universities throughout Asia and with diverse backgrounds in resource economics, engineering, human geography and philosophy. The paper was written collaboratively with each author contributing from his or her areas of specialization and in consultation with reviewers. Authors acknowledge the financial support of Ministry of Education, Culture, Sports, Science and Technology (MEXT), Japan.

\section{Notes}

1. Available at: http://ella.practicalaction.org/

2. Available at: www.jst.go.jp/global/english/kadai/index.html

\section{References}

Akiyama, T., Li, J. and Onuki, M. (2012), "Integral leadership education for sustainable development", Journal of Integral Theory and Practice, Vol. 7 No. 3, pp. 55-69.

Arrow, K., Bolin, B., Costanza, R., Dasgupta, P., Folke, C., Holling, C.S., Jansson, B.O., Levin, S., Maler, K.G., Perrings, C. and Pimentel, D. (1995), "Economic growth, carrying capacity, and the environment", Science, Vol. 268, pp. 520-521.

Brundiers, K. and Wiek, A. (2013), "Do we teach what we preach? An international comparison of problem- and project-based learning courses in sustainability", Sustainability, Vol. 5 No. 4, pp. 1725-1746.

Brundiers, K., Wiek, A. and Kay, B. (2013), "The role of interface managers in transformative sustainability research and education”, Sustainability, Vol. 5, pp. 4615-4636.

Burns, J.M. (1978), Leadership, Harper \& Row, New York, NY.

Facione, P. (1990), Critical Thinking: A Statement of Expert Consensus for Purposes of Educational Assessment and Instruction: Executive Summary, CA Academic Press, San Jose.

Froese-Germain, B. (2010), The OECD, PISA and the Impacts on Educational Policy, Canadian Teachers Foundation, available at: http://files.eric.ed.gov/fulltext/ED532562.pdf

Future Earth (2013), Future Earth Initial Design: Report of the Transition Team, International Council for Science, available at: www.icsu.org/future-earth/media-centre/relevant_publications/futureearth-initial-design-report

Hadorn, G., Bradley, D., Pohl, C., Rist, S. and Wiesmann, U. (2006), "Implications of transdisciplinarity for sustainability research", Ecological Economics, Vol. 60, pp. 119-128.

Hassenforder, E., Smajgl, A. and Ward, J. (2015), "Towards understanding participatory processes: framework, application and results", Journal of Environmental Management, Vol. 157, pp. 84-95.

ILEK project (2016), available at: http://en.ilekcrp.org/ (accessed 1 August 2016).

Kassiola, J. (2003), "Can environmental ethics 'solve' environmental problems and save the world? Yes, but first we must recognise the essential normative nature of environmental problems", Environmental Values, Vol. 12 No. 4, pp. 489-514.

Katz, D. and Kahn, R.L. (1978), The Social Psychology of Organizations (Revised Edition), Wiley, New York, NY.

Kikuchi, Y., Kanematsu, Y., Ugo, M., Hamada, Y. and Okubo, T. (2016), "Industrial symbiosis centered on a regional cogeneration power plant utilizing available local resources: a case study of Tanegashima”, Journal of Industrial Ecology, Vol. 20 No. 2, pp. 276-288. 
Lang, D.J., Wiek, A., Bergmann, M., Stauffacher, M., Martens, P., Moll, P., Swilling, M. and Thomas, C. (2012), "Transdisciplinary research in sustainability science - practice, principles and challenges", Sustainability Science, Vol. 7 (Supplement 1), pp. 25-43.

Lee, J.W. and Hong, K. (2012), "Economic growth in Asia: determinants and prospects", Japan and the World Economy, Vol. 24 No. 2, pp. 101-113.

Mauser, W., Klepper, G., Rice, M., Schmalzbauer, B.S., Hackmann, H., Leemans, R. and Moore, H. (2013), "Transdisciplinary global change research: the co-creation of knowledge for sustainability", Current Opinion in Environmental Sustainability, Vol. 5, pp. 420-431.

Metcalf, L. and Benn, S. (2012), "Leadership for sustainability: an evolution of leadership ability", Journal of Business Ethics, Vol. 112 No. 3, pp. 369-384.

Miller, T.R., Wiek, A., Sarewitz, D., Robinson, J., Olsson, L., Kriebel, D. and Loorbach, D. (2014), "The future of sustainability science: a solutions-oriented research agenda", Sustainability Science, Vol. 9, pp. 239-246.

Mochizuki, Y. and Fadeeva, Z. (2010), "Competences for sustainable development and sustainability: Significance and challenges for ESD”, International Journal of Sustainability in Higher Education, Vol. 11 No. 4, pp. 391-403.

Mumford, M.D., Zaccaro, S.J., Harding, F.D., Jacobs, T.O. and Fleishman, E.A. (2000), "Leadership skills for a changing world: solving complex social problems", The Leadership Quarterly, Vol. 11 No. 1, pp. 11-35.

OECD (2005), "The Definition and selection of key competencies", available at: www.oecd.org/pisa/ 35070367.pdf (accessed December 2015).

Ohara, S., Fukushima, Y., Sugimoto, A., Terajima, Y., Ishida, T. and Sakoda, A. (2012), "Rethinking the cane sugar mill by using selective fermentation of reducing sugars by Saccharomyces dairenensis, prior to sugar crystallization”, Biomass and Bioenergy, Vol. 42, pp. 78-85.

Ohara, S., Kato, T., Fukushima, Y. and Sakoda, A. (2013), "Selective ethanol production from a saccharide mixture", Journal of Biosciences and Bioengineering, Vol. 115 No. 5, pp. 540-543.

Oltheten, T.M.P. (1995), "Participatory approaches to planning for community forestry", Forests, Trees and People Programme - Forestry Department Working Paper No. 2, available at: www.fao.org/ docrep/006/x2103e/X2103E00.HTM\#TopOfPage (accessed 11 August 2016).

Ouchida, K., Fukushima, Y., Ohara, S., Sugimoto, A., Hirao, M. and Kikuchi, Y. (2016), "Integrated design of agricultural and industrial processes: a case study of combined sugar and ethanol production”, AIChE Journal, doi: 10.1002/aic.15374.

Paula, J.P., Selby, D. and Sterling, S.R. (2010), "More than the sum of their parts? Interdisciplinary and sustainability", in Paula Jones, P., Selby, D. and Sterling, S.R. (Eds), Sustainability Education: Perspectives and Practice across Higher Education, Earthscan, London, pp. 17-37.

Peleg, S. (2010), "Normative dialogue in a multi-cultural community: an analytical and practical model", Peace Studies Journal, Vol. 3 No. 2, pp. 33-48.

Reed, M.S., Kenter, J., Bonn, A., Broad, K., Burt, T.P., Fazey, I.R., Frazer, E.D.G., Hubacek, K., Nainggolan, D., Quinn, C.H., Stringer, L.C. and Ravera, F. (2013), "Participatory scenario development for environmental management: a methodological framework illustrated with experience from the UK uplands", Journal of Environmental Management, Vol. 128, pp. 345-362.

Reid, W.V., Chen, D., Goldfarb, L., Hackmann, Y., Lee, Y.T., Mokhele, K., Ostrom, E., Raivio, K., Rockstorm, J., Schellnhuber, J. and Whyte, A. (2010), "Earth system science for global sustainability: grand challenges", Science, Vol. 330 No. 6006, pp. 916-917.

Sato, T. (2014), "Integrated local environmental knowledge supporting adaptive governance of local communities", in Alvares, C. (Ed.) Multicultural Knowledge and the University, Multiversity India, Mapusa, pp. 268-273. 
IJSHE

18,2

Sun, P. and Anderson, M. (2011), "Civic capacity: building on transformational leadership to explain successful integrative public leadership", The Leadership Quarterly, Vol. 23 No. 3, pp. 309-323.

The World Commission on Environment and Development (WCED) (1987), Our Common Future, Oxford University Press, Oxford.

Thomas, I. (2009), "Critical thinking, transformative learning, sustainable education, and problem-based learning in universities", Journal of Transformative Education Vol. 7 No. 3, pp. 245-264.

Trencher, G., Terada, T. and Yarime, M. (2015), "Student participation in the co-creation of knowledge and social experiments for advancing sustainability: experiences from the University of Tokyo", Current Opinion in Environmental Sustainability, Vol. 16, pp. 56-63.

United Nations Educational, Scientific, and Cultural Organization (UNESCO) (2014), "UNESCO roadmap for implementing the global action programme on education for sustainable development", available at: http://unesdoc.unesco.org/images/0023/002305/230514e.pdf (accessed March 2016).

World Commission on Environment and Development (WCED) (1987), The Report of World Commission on Environment and Development Our Common Future, Oxford University Press, Oxford.

Wiek, A. and Kay, B. (2015), "Learning while transforming: solution-oriented learning for urban sustainability in Phoenix, AZ", Current Opinion in Environmental Sustainability, Vol. 16, pp. 29-36.

Wiek, A., Withycombe, L. and Redman, C.L. (2011), "Key competencies in sustainability: a reference framework for academic program development”, Sustainability Science, Vol. 6 No. 2, pp. 203-218.

Williams, P. (2002), “The competent boundary spanner", Public Administration, Vol. 80, pp. 103-124.

Yarime, M., Trencher, G., Mino, T., Schloz, R., Olsson, L., Ness, B., Frantzeskaki, N. and Rotmas, J. (2012), "Establishing sustainability science in higher education institutions: toward an integration of academic development, institutionalization, and stakeholder collaborations", Sustainability Science, Vol. 7 (Supplement), pp. 101-113.

Yukl, G.A. (2010), Leadership in Organizations, 7th edn., Person Prentice Hall, Englewood Cliffs, NJ.

\section{Further Reading}

Kates, R.W., Clark, W.C., Corell, R., Hall, J.M., Jaeger, C.C., Lowe, I., McCarthy, J.J., Schellnhuber, H.J., Bolin, B., Dickson, N.M., Faucheux, S., Gallopin, G.C., Grübler, A., Huntley, B., Jäger, J., Jodha, N.S., Kasperson, R.E., Mabogunje, A., Matson, P., Mooney, H., Moore, B., O'Riordan, T. and Svedlin, U. (2001), "Environment and development: sustainability science", Science, Vol. 292, pp. 641-642.

\section{Corresponding author}

Gakushi Ishimura can be contacted at: gakugaku@iwate-u.ac.jp

For instructions on how to order reprints of this article, please visit our website:

www.emeraldgrouppublishing.com/licensing/reprints.htm

Or contact us for further details: permissions@emeraldinsight.com 